\title{
A Buenos Aires de Ezequiel Martínez Estrada
}

\author{
Adrián Gorelik \\ Tradução de Ana Cristina Arantes Nasser
}

Todas as grandes cidades produzem esse gênero de literatura ensaística, que denominamos de "indagação sobre a metrópole", pois, desde sua formação, a grande cidade moderna tem aparecido como um importante enigma da vida social - um artefato sofisticado e complexo que revoluciona incessantemente as formas de relação tanto na esfera pública como privada, mas que, ao mesmo tempo, é naturalizado quase imediatamente pela sociedade urbana, graças a essa capacidade da cidade de plasmar as formas sociais em matrizes espaciais da cotidianidade: ruas e praças, edifícios e monumentos, então convertidos em indícios materiais de uma dimensão simbólica da vida moderna, que a cidade, simultaneamente, produz e encarna. Talvez essa seja uma das razões pelas quais ela sempre figurou no imaginário social como um território denso e supersignificado, povoado de chaves que se apresentam ao deciframento como uma trama policial; um território que, de um lado, constitui um dos fatores primordiais do desencantamento do mundo - o próprio mundo do desencantamento realizado -, mas cuja força simbólica e textura cifrada de seu espaço social parecem produzir, de outro lado, um reencantamento que incita à interpretação.

Por algum tempo relegado pela área do pensamento urbano, esse gênero de indagação tem sido revalorizado nas últimas décadas, com a importância 
1. Tomo a expressão "pensamento figural" de Franco Rella (1984, pp. 27 e 31), que seguiu o fio deste pensamento na crítica, na arte e na literatura centro-europeia das primeiras décadas do século. Analisei essa corrente de pensamento em relação à cidade em Gorelik (1999a). conquistada pela dimensão cultural no debate sobre a modernidade, identificando nas reflexões sobre a metrópole uma de suas principais fontes como o atesta o renovado interesse por uma figura como Georg Simmel: provavelmente, o primeiro autor que explorou conscientemente as afinidades entre um modo de pensamento figural, como o propiciado pelo ensaio, e uma realidade material, como a da cidade pletórica de configurações simbólicas por meio das quais é possível interrogar os fatos sociais, convertendo-se em peça fundamental entre o ensaio cultural e a teoria social ${ }^{1}$.

Sob esse ponto de vista, seria possível notar a alternância de dois ciclos, nas perspectivas de questionamento da cidade ao longo do século XX: se, nos três primeiros quartos do século, o pensamento urbano parece "avançar” do ensaio cultural à teoria sociourbana (a partir da extraordinária leitura feita de Simmel pela Escola de Chicago, por meio de combinações e reposições teóricas radicais, desenvolvidas em linhas bem diversificadas ecologia urbana, antropologia espacial, economia da localização etc. -, embora coincidentes na busca por uma sistematização científica crescente); em contrapartida, no último quarto do século, todo esse progresso parece ter se desfeito em um "retorno" às fontes culturalistas (um retorno que, novamente, colocou no centro Simmel e toda uma constelação de pensadores que dele procedia, especialmente Walter Benjamin).

Ao menos, foi desse modo que o debate pós-moderno o apresentou, na década de 1980 . Na realidade, se examinarmos mais atentamente outras dimensões do pensamento sobre a cidade, poderemos notar que desde a década de 1950 vinha ocorrendo uma irrupção de perspectivas culturalistas enfoques semiológicos, históricos, políticos -, que se traduziram em grandes correntes de reflexão urbana: produto da crise das convicções modernizadoras no espaço (a cidade) em que elas impuseram mais devastadoramente seus princípios durante as reconstruções do pós-Guerra, o que começou então a se romper foi um tipo de relato modernista que relacionava, mecanicamente, a cidade e o progresso, abrindo-se, assim, a caixa de Pandora das abordagens possíveis sobre a temática urbana, que coexistiram, durante um par de décadas, com os enfoques cientificistas, mas se destacaram no momento em que estes entraram em sua crise terminal.

No caso do ensaísmo sobre a cidade, essa relevância baseou-se em um duplo reconhecimento: o das dificuldades intrínsecas de uma teoria da cidade, já que a pluralidade transbordante do urbano converte a cidade em um objeto escorregadio e impermeável à sistematização teórica; e o reconhecimento da riqueza do ensaio cultural, não só por sua capacidade de captar 
processos de produção simbólica da cidade - que são, inclusive, fundamentais para a compreensão da dinâmica sociourbana -, como também por sua criatividade configuradora, sua inventividade para apresentar figuras simbólicas que atuam no imaginário social traduzindo a cidade, convertendo a realidade metropolitana em conhecimento social. Precisamente o aspecto mais combatido da produção ensaística, sua capacidade metafórica - essa economia ficcional que produz um constante deslocamento de sentido, do literal ao figurado -, acaba sendo reconsiderado em relação ao conhecimento da cidade, não só por sua acuidade perceptiva, mas também por sua eficácia performática.

Certamente, essa heterodoxia das últimas décadas, em relação à avaliação da produtividade das diferentes vias de interpretação do social, não é exclusiva do ensaísmo urbano: todas as ciências sociais empenharam-se em revisar a literatura produzida à margem da principal teoria sociológica e, além disso, validaram um novo procedimento de leitura dos clássicos, estabelecendo uma conciliação com a dimensão lírica de sua escrita, o que, indubitavelmente, já constitui um novo capítulo na história da "terceira cultura”, conforme denominação dada por Wolf Lepenies ao pensamento sociológico, sempre vacilante quanto à atração/oposição entre ciência e literatura $^{2}$. No entanto, as limitações epistemológicas das tentativas de abordagem científica da cidade produziram uma certa irrupção culturalista, de consequências provavelmente mais radicais: tudo o que a ciência urbana parece ter perdido ao reconhecer a irredutibilidade da cidade à teoria, o ensaio cultural parece ter ganho em graus de liberdade para abordá-la.

Ezequiel Martínez Estrada é o primeiro nome que surge quando se pensa na tradição do ensaísmo argentino; assim como é um dos primeiros quando se pensa no ensaísmo latino-americano ${ }^{3}$. Exatamente por isso, sua figura tem sido muito estudada, e também foi objeto de múltiplas interpretações o seu estilo de ensaio ontológico intuicionista - esse compositum histórico-filosófico, segundo Altamirano e Sarlo, que reúne "vários dos lugares-comuns do pessimismo filosófico com uma ética abstrata e um inconformismo moralista” (1983, p. 120). Entretanto, um de seus ensaios mais famosos e, certamente, o mais conhecido entre os que foram escritos sobre Buenos Aires, La cabeza de Goliat. Microscopía de Buenos Aires, de 1940 , não recebeu muita atenção, sobretudo comparativamente a outros

2. Ver Lepenies (1994); sobre as leituras dos clássicos, ver Nisbet (1979).

3. Sobre Martínez Estrada, ver o artigo de Carlos Altamirano, neste mesmo Dossiê. 
4. O crítico uruguaio Emir Rodríguez Monegal chamou de "geração parricida" o grupo reunido em torno de H. A. Murena, e depois, na revista Contorno, na década de 1950; Martínez Estrada foi um dos "pais" com os quais se produziu a relação mais ambígua e conflitante (a revista reivindicava para si uma atitude "denuncista”, também encontrada no autor de La cabeza de Goliat); ver Monegal (1956). dois ensaios que completam sua trilogia clássica: Radiografía de la pampa, de 1933, o de maior impacto e ao qual se dedicou a maior quantidade de estudos, e Muerte y transfiguración del Martín Fierro, de 1948, que o projetou entre a geração "parricida" da década de 1950, não mais como inspiração para o "denuncismo", mas sim como um inovador da crítica literária ${ }^{4}$. Aqui, propomo-nos a analisar La cabeza de Goliat como um reservatório de correntes muito diversas na literatura sobre Buenos Aires - como um precipitado de figuras da metrópole -, tentando entender, por meio dessa obra, como se formam e de onde provêm as representaçôes da cidade e, finalmente, como se deram entre nós as batalhas da "terceira cultura" na temática do urbano.

La cabeza de Goliat é, certamente, um livro muito difícil de apreender em esquemas interpretativos consistentes, devido à sua estrutura episódica (uma "coleção de instantâneos", como o denominou David Viñas, em uma das raras caracterizaçôes realizadas), que o torna muito mais frágil do que Radiografía de la pampa, ainda que se mantenham os traços principais da escrita martinezestradiana: esse fluxo de paradoxos e inversões lógicas, metáforas luminosas e análises sagazes, geralmente perdidos no turbilhão de uma argumentação exclusivamente sustentada por sua capacidade lírica (cf. Viñas, 1993, p. 413). Entretanto, esse caráter fragmentário também torna La cabeza de Goliat - e esta é uma das principais hipóteses que organizam nossa leitura - uma obra muito mais porosa, ideologicamente, do que $R a$ diografía de la pampa. O livro apresenta-se como um close-up sobre Buenos Aires, em direta continuidade com as hipóteses e os modos de leitura já estabelecidos em Radiografía..., como se sublinha nos seus próprios títulos, conectados pelo jogo de metáforas da observação científica. Ou seja, estão novamente presentes tanto o fatalismo racialista dos positivistas argentinos da virada do século, como o simbolismo dos "alemães intensos" - conforme a definição formulada, não sem deboche, por Jorge Luis Borges, ao resenhar o primeiro dos ensaios (cf. Borges, 1933, p. 5). Borges mencionava a presença, em Radiografia de la pampa, do estilo interpretativo de Oswald Spengler, Hermann Keyserling e Waldo Frank, englobando uma constelação de autores reconhecida por todos os comentaristas, e cuja importância na cultura argentina, nas décadas de 1920 e 1930, excedia amplamente as preferências estilísticas de Martínez Estrada: Spengler usufruía de seu momento de maior celebridade internacional, devido às recentes traduçóes da Revista de Occidente, dirigida por José Ortega y Gasset, que juntamente com Keyserling e Frank compunha o trio de viajantes que, no final da 
década de 1920, realizou uma série de interpretações da Argentina, em torno da qual gravitaria boa parte do ensaísmo local na década posterior ${ }^{5}$.

O próprio Martínez Estrada apresentaria um elenco ainda mais "alemão": "Até o mais míope [...] teria conseguido perceber que a configuração de Radiografía de la pampa deve a Spengler, por sua leitura simbólica dos fatos, a Freud, por sua análise das perturbações da psiquê social, e também a Simmel, por seu método configuracionista [...] mestre de método e de prosa” (Estrada, 1969, p. 134). Além disso, em La cabeza de Goliat, pode-se encontrar, sob o ponto de vista que aqui importa, o pensamento figural e também a matriz espacial nas explicaçōes sobre a sociedade e a cultura, elementos decisivos na indagação sobre a metrópole, que se traduziam como uma metaforização da cidade e do território ${ }^{6}$.

Há expressiva continuidade entre os dois primeiros ensaios de Martínez Estrada. De fato, no primeiro deles, Buenos Aires já era uma protagonista quase excludente, dentro de uma tradição interpretativa de denúncia da desproporcionalidade entre a cidade-porto e o país, e também no âmbito de uma representação dessas relações "capitais" na história nacional, segundo a qual toda a Argentina encontrava sua desembocadura natural no Prata, e, portanto, no pampa e em Buenos Aires, igualados em sua qualidade de condensação das chaves nacionais. La cabeza de Goliat oferece novamente uma fábrica de metáforas para essa relação entre a cidade e o pampa, embora o próprio título aponte a importância, naquele momento primordial, da tradição de denúncia sobre as relações entre Buenos Aires e o país: oriunda da crise do projeto modernizador do final do século XIX, tal denúncia ficará definitivamente cristalizada na imagem da "cabeça de Goliat”, ratificando, mais uma vez, o talento figurativo de Martínez Estrada.

Já nas primeiras páginas do livro, retomam-se os dois argumentos centrais da acusação contra Buenos Aires. De um lado, suas tendências isolacionistas - um antigo argumento, ao qual José María Ramos Mejía dedicou, em 1907, um capítulo importante em Rosas y su tiempo, buscando explicar, por meio do temperamento mercantil, individualista, conservador e extremamente baseado no localismo da cidade (o termo com o qual o qualifica é "patriotismo urbano", muito explorado em La cabeza de Goliat), o apoio que, em sua época, Rosas encontrou na elite de Buenos Aires. E, de outro lado, o argumento sobre o caráter "artificial" da cidade, apontando que a origem e o desenvolvimento de Buenos Aires baseavam-se em razóes e mecanismos político-institucionais (a centralização, com todas as suas implicações ulteriores: o monopólio do porto, o traçado da ferrovia, a atra-
5. María Teresa Gramuglio analisou a continuidade da discussão com os três viajantes num ensaio da década de 1930. Ver Gramuglio (2001).

6. Sobre a interpretação do "imaginário espacial" de Spengler, em Radiografia de la pampa, ver Gorelik (2004a). Sobre a referência a Freud por Martínez Estrada, Hugo Vezzetti (2007, p. 2) apontou uma dimensão simbólica semelhante: uma "apropriação do freudismo como hermenêutica do latente". 
7. Todas as citações do livro derivam desta edição, e serão aqui assinaladas entre colchetes, com o número da página correspondente ao final. ção da população imigrante etc.), e não em genuínas potencialidades geoeconômicas, seguindo uma posição proveniente da antropogeografia, apresentada na Argentina por Juan Álvarez, em seu livro Buenos Aires, de 1918. A partir desses argumentos, Martínez Estrada constrói boa parte de seu conjunto de teses, expostas como juízos apodíticos e paradoxais: "Buenos Aires é uma grande máquina, que [...] absorve brutal e cegamente a riqueza do interior, devora pressupostos fantásticos, e come, como todo gigante, pela boca de sua cabeça cortada. Alimenta-se da miséria e do atraso, da ignorância e da solidão. Buenos Aires é um muro no horizonte urbano, impedindo que se olhe o interior" (Estrada, 1983, p. 84)7.

Mas, se esses são os pontos de partida comuns entre a Buenos Aires de Radiografía de la pampa e a de La cabeza de Goliat, fica evidente que unicamente com base na tradição de indagação e denúncia Martínez Estrada não poderia ter escrito um livro sobre a cidade: o close-up (o microscópio) promete um ponto de vista diferente - não só mais próximo, como interno à metrópole. Para obtê-lo, La cabeza de Goliat utiliza um recurso retórico: converte o paradoxo relacional fundamental - "Erguemos uma grande cidade, porque não soubemos erguer uma grande nação" [p. 153] - em um instrumento analítico, sob o argumento de que sobre cada um dos temas de Buenos Aires seja preciso confrontar duas perspectivas de juízos contrastantes: a urbana e a nacional. Para o livro, essa dupla perspectiva é importante, num sentido estratégico, para desfazer os mal-entendidos gerados pela observação focada na cidade (pois, vendo-se Buenos Aires sem o país, acredita-se que ela é "um portento de poder e vitalidade", e se esquece de que sua riqueza provém do interior e que ela "agiu com essas contribuições sagradas" para engrandecer-se como urbe, e não como Capital da Nação [p. 21]); mas, além disso, ela é, sobretudo, taticamente importante para conferir certa autonomia a uma análise interna de Buenos Aires como a grande metrópole, que também o é. Assim, Martínez Estrada encontra em seu próprio sistema figurativo um recurso analítico que lhe serve para se dedicar - sem perder de vista os juízos gerais sobre o país, aos quais sempre retorna - ao exame das questôes especificamente urbanas, organizando todo o livro sobre esse duplo andarivel.

Por exemplo, o fato de que a ferrovia continue sendo uma de suas metáforas favoritas para denunciar um "progresso nacional” que só beneficiou a 
cidade-porto (em seu papel de intermediária dos interesses ingleses, que desenharam o sistema ferroviário como uma teia de aranha que tece suas redes sobre o país) não o impede de também analisá-la como meio de transporte de Buenos Aires, onde assume um papel metafórico oposto, já que, em contraste com a velocidade muito superior dos mais modernos ônibus urbanos e dos metrôs (o meio de transporte que melhor simboliza a vida mecanizada da urbe), o trem constitui uma tecnologia decadente, cuja lentidão passa a representar aquela do país [pp. 37ss.]. O certo é que essa dupla visão lhe permite tomar outro rumo em relação a temas tão sensíveis no contexto de seus juízos mais gerais sobre os papéis da cidade na nação, bem como desenvolver, sem cair em contradições aparentes, outro tipo de argumentação - como no presente caso - sobre os transportes e as diferentes velocidades da metrópole.

De modo mais geral, essa dupla visão lhe permite ainda abordar uma questão fundamental em La cabeza de Goliat, bem como em qualquer indagação sobre a metrópole: a própria modernidade. Isso porque, na perspectiva nacional de Buenos Aires, Martínez Estrada não se preocupa com a modernidade em si, mas com os efeitos paradoxais de sua imposição artificial sobre um território refratário a ela, que tergiversa as supostas virtudes do progresso em novas máscaras sob as quais pode dissimular hábitos ancestrais. Assim, é em Radiografia de la pampa que a modernidade constitui, na chave spengleriana, a última das pseudoestruturas que foram aplicadas sobre o país, obstruindo o seu desenvolvimento orgânico: um dispositivo ortopédico que deforma o território unicamente em benefício de sua exploração. Nesse sentido, Buenos Aires constitui o principal instrumento dessa imposição ortopédica, uma fábrica de representaçōes falsas sobre o progresso e a modernidade, que funcionou entre os intelectuais do século XIX Sarmiento, principalmente - como "um transtorno imaginário" (Estrada, 1993, p. 254).

Essa perspectiva se mantém nos primeiros capítulos de La cabeza de Goliat, embora lentamente se produza a mudança radical para a perspectiva urbana propriamente dita, que apresenta uma modernidade muito diferente; uma modernidade que, na vereda de Simmel, Martínez Estrada vê não só intensificada na cidade, mas também como fundamento último dos menores objetos da paisagem urbana e dos comportamentos convencionais de seus habitantes: a metrópole como coisificação da modernidade. O capítulo de transição entre as duas perspectivas intitula-se, significativamente, “'Tempo' americano de la ciudad”, no qual aparece, por exemplo, um mote 
constante em todo o livro: o da "neurose das grandes cidades" [p. 34], e que Martínez Estrada coloca entre aspas para indicar, como poderíamos pensar, mais do que uma dívida teórica, a sua extensão como lugar-comum, em 1940. Trata-se de um capítulo de transição, pois se baseia na convicção de que a referida neurose, apesar de diagnosticada primeiro nas metrópoles europeias - mais exatamente, em Berlim -, é específica da América, “o continente do movimento e da velocidade" [p. 34]; em nossas cidades, a simples aparência é acompanhada pela fugacidade, configurando um círculo de precariedade e decadência. Assim, para estabelecer a ponte entre a aparência de progresso da Buenos Aires nacional e a neurose da Buenos Aires metropolitana, Martínez Estrada declina um lugar-comum já utilizado por Borges - o tempo passa mais rápido nas cidades sem história -, e que plasmaria LéviStrauss em seu conhecido dictum sobre as cidades americanas que passam do viço à decrepitude, sem nunca terem chegado a ser antigas.

A partir desse ponto do livro, vão surgindo todos os temas da modernidade urbana, em um conjunto heterogêneo, que pode derivar tanto de Simmel - a vida mecanizada e racional (com o relógio como "coração da cidade" [p. 48]), o nomadismo do habitante metropolitano e sua personalidade fragmentada -, como de Weber - a cidade como manifestação extrema do cárcere de ferro [p. 56] -, embora com um ar de reprovação antiurbana muito mais próximo de Spengler. Ou, melhor, assim como no livro se produz uma aclimatação da neurose simmeliana, tornando-a uma característica especificamente americana, há também uma moralização das análises da sociologia alemã da modernidade, convertendo a vida metropolitana em algo execrável, uma invenção “diabólica” [p. 52]. Por isso o tom spengleriano ao denunciar a mercantilização do lar como sinal de decadência [p. 62], ao explicar a existência do prédio de apartamentos pelo utilitarismo dos estrangeiros (a "aspiração do hóspede que não ama o país" [p. 64]), ou ao identificar o comer fora com o adultério [p. 60].

Trata-se de uma moralização das análises sobre a modernidade, que acaba por introduzir uma explicação ideológica completamente diferente entre a perspectiva nacional e a urbana. Isso porque, em Radiografia de la pampa, o amálgama ortopédico entre modernidade e tradição criou uma nova realidade na qual "civilização e barbárie eram uma mesma coisa"; uma verdade profunda que devia ser trazida "à consciência, para que se desvaneça e possamos viver unidos na saúde" (Idem, p. 256), conforme a conhecida frase que finalizava o livro. Por sua vez, em La cabeza de Goliat, enquanto se trata da perspectiva nacional, a modernidade segue a mesma linha de análise; embo- 
ra, na perspectiva metropolitana, seja confrontada com uma alternativa reparadora: longe de fazer parte de uma verdade única, que simplemente é preciso compreender e aceitar para que tenha início o processo terapêutico da superação, a modernidade é, então, considerada a partir de uma nostalgia antimetropolitana, que encontra consolo tanto nas recordações da cidade pré-moderna, como na vida extraurbana, na qual inclusive o pampa pode aparecer sob uma luz celebradora: "o pampa é também movimento, mas não pessimismo e desalento, e sim exercício e saúde" [p. 114] - esclarece Martínez Estrada em resposta aos críticos de Radiografía...

A essa altura, é possível formular a hipótese de que as referidas mudanças de registro ideológico entre Radiografia de la pampa e La cabeza de Goliat não podem ser compreendidas como transformações no pensamento de Martínez Estrada, já que em obras posteriores ele mantém posições muito próximas de Radiografia..., a não ser como uma imposição da temática urbana: a dupla perspectiva que torna retoricamente possível a indagação sobre a metrópole (o close-up sobre Buenos Aires) leva Martínez Estrada a uma chave de explicação dualista da realidade, que não se verifica em seus outros trabalhos e que abre La cabeza de Goliat para outras linhas do pensamento sobre Buenos Aires.

De fato, a ausência de modelos binários pode ser apontada como uma das principais características de Radiografía de la pampa, diante de outras tradiçōes do ensaio; por exemplo, a do regeneracionismo do Centenário, que havia invertido a fórmula sarmientiana, situando a barbárie na babel de fábrica em que a modernização convertera Buenos Aires, e também identificando nas províncias a fonte de civilização autêntica em que radicava a cultura nacional; ou então a derivação mais contemporânea dessa tradição, que expressava na ideia das "duas Argentinas" uma espécie de impugnação à cultura urbana, com base na dicotomia maurrasiana entre "país falso/país verdadeiro", de notável difusão na década de 1930, e uma de cujas encarnaçōes mais célebres organiza todo o ensaio rival a Radiografía de la pampa: a oposição entre o país "visível” e o "invisível”, em Historia de una pasión argentina (cf. Maella, 1937) ${ }^{8}$.

Mas se Radiografía... não oferecia nenhuma contrapartida positiva aos males do país - visto que nesse relato não poderia haver um país "verdadeiro" oposto a um "falso", já que Buenos Aires aí constituía a expressão mais defi-
8. Sobre o tema das "duas Argentinas”, ver Gorelik (1999b). 
9. Sigal é quem melhor estabeleceu as relações entre a vida e a obra de nosso autor, em uma tese de 1982 (Martínez Estrada et le milieu argentin de la première moitié du XXe siècle), na qual duas partes podem ser lidas em "Itinerario de un autodidacta" e "La radiografía de la pampa: un saber espectral", quesão os capítulos de sua autoria na supracitada edição. nitiva de ambos, sendo que nesse emaranhado, que a tudo contamina, residia seu caos e sua condenação -, La cabeza de Goliat, em contrapartida, está permanentemente permeada por visóes muito mais reconciliadas com o "país interior", e apresentadas como contraste da metrópole, assumindo, tal qual o regeneracionismo, uma ideia de "interior" que reforça a ligação espiritual entre autenticidade e profundidade diante da mera aparência, superficial e enganosa, da cidade-porto. Assim, Martínez Estrada encontra "terra adentro" não só a antítese de Buenos Aires como seu antídoto, o remédio para os males que a cidade Capital inflige ao restante do país e a si mesma.

Essa atitude consoladora se dará na dimensão propriamente urbana da análise, por meio da oposição passado/presente, em uma variante nostálgica também anômala em relação à forma de argumentação de Radiografía..., já que aí a história não era senão uma cadeia ininterrupta de catástrofes que remontava à mesma configuração geológica do pampa. Por sua vez, La cabeza de Goliat é muito sensível a tudo o que Buenos Aires parece ter perdido durante a sua modernização - ou a tudo o que consegue continuar contradizendo-a. Por exemplo, em um capítulo sobre as demolições, critica-se que Buenos Aires careça de memória, viva constantemente fugindo, destruindo no caminho um passado arquitetonicamente muito pobre, mas que "tinha um grande significado histórico", já que "o passado é a unidade cidadã" [pp. 78-79].

Seria como se o foco sobre a cidade impusesse a Martínez Estrada uma perspectiva superada, levando-o à sua primeira fase de poeta, com a qual Radiografía... buscara cortar qualquer vínculo - aquela fase em que sua participação na cultura oficial integrava-o ao círculo dos "argentinos de velha cepa [...] ideologicamente identificados com o passado heroico ou rural anterior à imigração" (Sigal, 1993, p. 373) ${ }^{9}$. E eis que em La cabeza de Goliat o referido retorno se apresenta sob a forma que melhor retrata aquele núcleo ideológico na literatura sobre Buenos Aires, o memorialismo - gênero certamente consubstancial por excelência com a metrópole, visto que sempre aparece como reação diante da aceleração das transformações produzidas em toda modernização urbana, quando se assiste, em uns poucos anos, ao desaparecimento de qualquer paisagem familiar à qual se retorna com espírito descritivo e testemunhal, declinando um mote fundamental em todo decadentismo: o progresso material é acompanhado da miséria espiritual.

Em Buenos Aires, a tradição memorialista teve início como literatura das elites portenhas, exatamente no momento de afirmação da modernização por elas projetada; ou seja, em 1880, ano em que a cidade finalmente se 
torna capital federal, solucionando uma crise que, durante grande parte do século XIX, impedira a consolidação institucional do Estado-nação; e também época em que o memorialismo descobre a cidade criolla condenada à extinção, e busca retratá-la amorosamente: Buenos Aires desde setenta años atrás, de José Antonio Wilde, em 1881; La gran aldea, de Lucio V. López, em 1884; Las beldades de mi tiempo, de Santiago Calzadilla, em 1891, são alguns de seus títulos mais emblemáticos. Em La cabeza de Goliat, o memorialismo aparece de dois modos: como declinação de um tom melancólico, nas mil variáveis do ubi sunt, com essa conexão tipicamente memorialista entre a perda da infância individual e a perda de uma infância da metrópole (é dessa forma, por exemplo, que Martínez Estrada considera o carnaval: "Na minha infância, o carnaval impunha respeito e algumas máscaras atemorizavam [...]. Mais tarde, o espírito festivo e religioso se perdeu, e teve início a decadência" [p. 313] $)^{10}$; como recurso de periodização, já que $L a$ cabeza de Goliat "encerra" a história da cidade, em 1880, estabelecendo aí um divisor valorativo sob o qual se estende homogêneo o presente em que escreve, no final da década de 1930. Isso se enuncia desde o início do livro, quando se explica o caráter de Buenos Aires pela superposição estratigráfica de quatro eras urbanas irresolutas: a da primeira fundação, em 1536 (a cidade do medo e da solidão); a da segunda fundação, em 1580 (a da valentia); a da emancipação, em 1810 ("a cidade dos próceres, a única cidade nossa”); e a da modernização, em 1880 (“a cidade de todos e de ninguém”, "persistente e de chumbo") [pp. 17-19]. A cidade de todos e de ninguém: poucas definiçóes expressam mais claramente o desgosto da elite portenha finissecular com a federalização de Buenos Aires, considerada como alienação inevitável - condição-chave da unificação nacional e da afirmação do projeto modernizador -, mas nem por isso menos ultrajante.

\section{5}

No entanto, a recusa de La cabeza de Goliat à modernidade metropolitana vai bem mais além da ambiguidade memorialista, instalando-se em pleno clima ideológico do Centenário, já que sua valorização dualista considera que a cidade de 1880 não apenas é a "que é indiferente ao interior e olha para a Europa" [p. 19], mas é também, particularmente, aquela em que "a alma envelheceu e as pessoas se misturaram e se impregnaram, reciprocamente, com a escória trazida dos países europeus" [p. 169]. Em La cabeça de Goliat, a presença contundente dos anátemas contra a imigração
10. O capítulo "Buenos Aires", de Radiografía de la pampa, também tinha um apêndice intitulado "Carnaval y tristeza”, mas aí a relação era vista como estrutural a toda a história do carnaval criollo, pensado como expressão não só da tristeza do caráter argentino, como da crueldade, do desespero e da hostilidade; esse apêndice termina com um episódio, contado por Sarmiento - a respeito de uma máscara que, na província, fora queimada pelo público -, e que Martínez Estrada vê novamente acontecer cem anos depois, em um carnaval em Buenos Aires. Ver Estrada (1993, pp. 165 ss.). 
impacta com um efeito anacrônico, como se o livro tivesse sido escrito vinte anos antes de Radiografía de la pampa.

Certamente, a questão da imigração também estava presente nesse primeiro ensaio de Martínez Estrada: ela constituía uma das variáveis inevitáveis no repertório dos "males nacionais", o caráter "aluvial" da população. Mas, além de certos juízos comuns sobre os efeitos da condição imigratória - individualismo, provisoriedade dos vínculos com o país, obsessão por fazer fortuna -, bem como das críticas já convencionais às políticas do século XIX, que pretenderam modificar radicalmente a população, o núcleo de Radiografía... se situava em outra parte: no combate desigual - perdido de antemão - entre a solidão cósmica da natureza do pampa e todo projeto humano; diante do pampa onipotente e inóspito de Radiografía..., os homens que habitaram esta terra se sentiram sempre estranhos a ela, estrangeiros em um sentido existencial; e a preocupação tipicamente positivista com a "promiscuidade das raças" estava focada muito mais na mestiçagem do que na imigração europeia - última cena, em todo caso, de um drama de séculos.

Contudo, em La cabeza de Goliat, o surpreendente a propósito de qualquer tema são as constantes acusações à imigração, de uma forma que extrapola o argumentativo para converter-se em adjetivação denegridora, como, por exemplo: a investida de um automóvel no trânsito consiste em "uma raiva de gringo" [p. 37]; os entregadores de mercadorias "regularmente estrangeiros" dão um tratamento brutal a seus cavalos, "símbolo do portenho em extinção" [p. 41]; a multiplicação dos prédios de apartamentos, emblemas do anonimato metropolitano, deve-se, conforme já mencionado, "aos gostos da imigração" e aos hábitos do "hóspede que não ama o país" [p. 64] porém, é mais comum que o crescimento vertical da cidade seja explicado pela imigração, porque "o estrangeiro se multiplica para cima e o nativo para o campo", e isso se expressa, por antonomásia, no centro da cidade, onde "a riqueza comercial e o conforto" foram gerados por "aerólitos de naçôes estranhas" que se alojaram nesta terra [p. 86] -; a explicação para que tantos edifícios históricos sejam demolidos é "o sentimento estrangeiro de vergonha filial" que acomete os vereadores [p. 79]; ou, então, Guillermo Enrique Hudson - uma das figuras mais admiradas por Martínez Estrada - deixou o país "quando os imigrantes principiavam sua obra destruidora" [p. 243]; e ainda poderíamos continuar enumerando dezenas de exemplos. A identificação criollista do autor é tal que ele até cai na artificialidade de contrapor ao gosto atual do portenho - "mecânico e cosmopolita" - o "paladar nacional" 
do cardápio de nossos avós" [p. 119], sendo ele, como nenhum leitor podia ignorar, filho de imigrantes.

Assim como ocorre em quase todos os temas abordados por Martínez Estrada, sobre os quais é possível encontrar afirmaçōes antitéticas em um mesmo parágrafo, também La cabeza de Goliat contém passagens de compreensão mais objetiva, embora excepcionais: a tônica dominante é a da impugnação aos estrangeiros como uma das principais razóes do mal moderno metropolitano, em uma identificação clássica do Centenário argentino, quando a combinação entre modernização e imigração aparecia como a fonte de um diagnóstico dilacerado, pois, mesmo sendo um dos primordiais motivos da "grandeza" de Buenos Aires a se celebrar, demonstrava, simultaneamente, as carências constitutivas de história e identidade (uma cidade que se refez sobre si mesma nos últimos vinte anos, e em que mais da metade da população era estrangeira). Trata-se, aqui, do argumento da pátria como perda dolorosamente encarnada na cidade Capital, cosmopolita e alheia, que é possível encontrar nos textos de Manuel Gálvez ou Ricardo Rojas, expoentes principais do regeneracionismo, ainda que separados pelo otimismo de Rojas sobre a capacidade inclusiva de uma restauração nacionalis$t a$, igualmente dirigida às massas imigrantes (cf. Gálvez, 2001; Rojas, 1971). Muito mais próximo do nacionalismo aristocrático de Gálvez (e de Leopoldo Lugones, citado abundantemente em La cabeza de Goliat), do que da aposta de Rojas em um culto maciço à ideia de Nação, Martínez Estrada novamente proporá o referido argumento quase sem alteraçôes, em 1940, quando a questão da definição do caráter e da identidade de Buenos Aires e seus habitantes parecia completamente resolvida.

Com efeito, a crônica jornalística vinha registrando, desde antes da década de 1920, o fenômeno da mistura nacional e social vertiginosamente produzida nos novos bairros populares; e nem poderia ter sido de outra forma, já que essa nova realidade sociourbana tinha gerado a expansão do público que explicava não só a própria existência desses jornais modernos, como também o novo protagonismo, na política da cidade, de um progressismo constituído nas duas forças destinadas a representar a população do bairro, o socialismo e o radicalismo. Assim, por volta de 1918, o bairro popular - cuja existência apenas se esboçava na época das celebrações do Centenário, alguns anos antes - ganha uma presença decisiva na vida política e cultural da cidade; efetivamente, as duas expressóes culturais mais significativas de Buenos Aires, o tango e o futebol, nasceram nesses bairros e, já na década de 1930, conseguiam vencer qualquer resistência aristocrá- 
11. Sobre a Buenos Aires das águas-fortes de Arlt, ver o estudo introdutório de Sylvia Saítta (1993).

12. Apontou-se muitas vezes que um dos objetivos principais das vanguardas literárias argentinas foi a invenção de um "idioma nacional", capaz de neutralizar os acessos do cocoliche imigrante. Ver a clássica análise de Beatriz Sarlo (1983). [Cocoliche é o jargão usado por imigrantes italianos na região do Prata (N. T.).] tica, impondo-se como o traço distintivo da cidade. Não se pode esquecer que, nos anos de 1920, o bairro é o cenário em que se integram culturas estabelecidas e marginais, velhas e novas, por meio de "mil fios sutis", que, como assinalou José Luis Romero, "acabaram criando uma trama comum, na Buenos Aires de 1930” (Romero, 1970, p. 323). As águas-fortes publicadas por Roberto Arlt no jornal El Mundo, a partir de 1928, são o melhor registro dessa nova trama, assim como de um novo tipo de indagação sobre a metrópole - herdeira dos cronistas finisseculares, como Fray Mocho, mais etnográficos do que introspectivos -, no qual a mistura social e nacional do bairro constitui a base naturalizada sobre a qual transcorrem histórias que têm esse novo público metropolitano não só como destinatário, mas também como protagonista ${ }^{11}$.

Por outro lado, essas mudanças também permaneceram registradas na reflexão que algumas figuras das vanguardas literárias desenvolveram sobre a identidade de Buenos Aires, na década de 1920 - fato esse duplamente significativo para o nosso argumento, já que bem se sabe da importância que o dilema introduzido pela imigração teve para as vanguardas argentinas, que responderam a ele com um exacerbado nacionalismo cultural ${ }^{12}$. Mas, mesmo assim, é notório que ao longo da década buscaram-se várias fórmulas de negociação com a heterogênea realidade social e cultural, conforme se verifica nos poemas e nos ensaios de Jorge Luis Borges, um dos vanguardistas mais preocupados com a fundação (mitológica) de um caráter criollo para a cidade. Com efeito, os escritos do jovem Borges, na década de 1920, buscavam explicitamente a "essência criolla" de Buenos Aires, para nela radicar a "epopeia" capaz de dar forma a uma identidade cultural para a cidade, mesmo encontrando-a nos arrabaldes, onde não só se misturavam a cidade e o pampa, como, particularmente, mesclavam-se todas as nacionalidades da sociedade popular formada nos bairros suburbanos.

A vanguarda contribui para processar culturalmente essa integração, por meio de diferentes narrativas. Por exemplo, ao identificar nas humildes casinhas suburbanas dos imigrantes um sabor "classicista" (produto de um saber artesanal dos construtores italianos que trouxeram em sua bagagem uma inconsciente matriz latina), que alinhava essas casinhas despojadas com a branca e sóbria Buenos Aires criolla, tal qual aparecia nas gravuras do século XIX; ou seja - e esta seria a fórmula dos ensaios e poemas de Borges, assim como das fotografias de Horacio Coppola, seu companheiro de caminhadas pelo subúrbio -, as casinhas alvejadas, com seus modestos pátios, assim como as ruas retas e a extensão plana do arrabalde, permitiam recupe- 
rar uma "patricialidade" perdida na cidade tradicional, afetada pela modernização urbana ${ }^{13}$. Ou então, ao postular, com uma espécie de telurismo otimista muito comum nas vanguardas locais, que o "espírito da terra" - do qual, mais tarde, zombaria um de seus cultuadores, Leopoldo Marechal, na desopilante excursão ao bairro de Saavedra de Adán Buenosayres - produzia efeitos de aclimatação cultural traduzidos na rápida criollização do imigrante; como também a fórmula que pode ser encontrada em El hombre que está solo y espera, o bem-sucedido ensaio de Raúl Scalabrini Ortiz, publicado em 1931. E ainda uma versão interpretativa que se consolida em 1936 (na avalanche de publicaçóes e comemoraçóes impulsionada pelo Quarto Centenário da Primeira Fundação da cidade), e que continuará sendo reproduzida já convencionalmente na literatura sobre Buenos Aires empenhada em mostrar que a miscigenação já se produziu com êxito, por ter dado forma a uma cidade pujante e original - constatação que surge nitidamente em livros como a Geografía de Buenos Aires, de Florencio Escardó (1945), ou a Biografia de Buenos Aires, de Pablo Rojas Paz (1951).

A Buenos Aires de La cabeza de Goliat é imune a essas convençōes otimistas, estando novamente povoada por um mal-estar em relação à imigração, que, mesmo em seu anacronismo, parece capaz de sintonizar um novo mal-estar, completamente diferente, embora análogo àquele. Uma das principais razôes para a consolidação das versões que davam por encerrada a fase de instabilidade social e cultural na cidade reside no fato de que na segunda metade da década de 1930 começara um novo processo imigratório, que produziria a segunda revolução demográfica de Buenos Aires, desta vez com migrantes internos (das províncias e dos países limítrofes) assentados em novos subúrbios ao redor da cidade Capital (o conjunto de bairros denominado "Grande Buenos Aires"). Uma nova "heterogeneidade" (terra adentro), que, opostamente, estabelecerá a autorrepresentação "homogênea” (europeia) da cidade Capital, com a construção da moderna via de circunvalação, a avenida General Paz, que começou a ser construída em 1936 e "fechou" a cidade para a Grande Buenos Aires provinciana.

Trata-se de um fenômeno que, como tal, passou despercebido por quase todos os observadores, até o início dos anos de 1940; mais simbolicamente, até 17 de outubro de 1945, quando “irromperam”, na Praça de Maio, aquelas "massas obscuras" que se aglomeravam na entrada da cidade nos anos ante-
13. Para uma análise dessa narrativa de vanguarda, ver Gorelik (2004b). 
14. Nos capítulos "Estadios" e "Regreso", Martínez Estrada faz uma análise das massas urbanas, parecendo antecipar a visão brutal sobre o peronismo, apresentada por Borges e Adolfo Bioy Casares, no conto "La fiesta del monstruo" (Crónicas de Bustos Domecq, 1967). O espetáculo desportivo é visto, por Martínez Estrada, como purgação da energia e da hostilidade atávica da sociedade, repetindo novos rituais no estádio ou no parque: "tumores dominicais e festivos", "conglomeraçōes adventícias" que se espalham pela cidade em caminhôes, com "gritos, atitudes vociferadas e jogadas na cara dos transeuntes, baforadas de ancestrais hálitos da caverna”. Esses grupos "podem polarizar por qualquer motivo análogo. São os que também engrossam as manifestaçōes políticas em multidóes que entoam os mesmos estribilhos [...]" (pp. 303-304). riores, estabelecendo, desde então, uma ligação indescritível com o peronismo. Insistindo em um mal-estar antigo - que tratava de combinar com sua análise mais contemporânea sobre "a monstruosa fisionomia passional" gerada pelos consumos culturais das multidões as "massas disformes, montôes de escombros humanos" que locupletam os estádios e os parques, aos domingos -, La cabeça de Goliat parece mais aberta a novas visóes de uma sociedade fragmentada do que aqueles diagnósticos otimistas, que simplesmente reforçavam por omissão a nova cisão social e urbana entre a capital e a Grande Buenos Aires ${ }^{14}$.

A própria existência da Grande Buenos Aires gera, no livro, um descompasso temporal similar, já que Martínez Estrada também fala muito pouco sobre essa novidade urbana inocultável na segunda metade da década de 1930: ele reclama de uma expansão ilimitada da cidade, que "fagocitou" as localidades suburbanas "em um maciço contínuo" [pp. 76-77] - embora abstratamente, como na década de 1910. De fato, em La cabeça de Goliat, segue-se definindo a estrutura geográfico-cultural da cidade nos mesmos termos de Radiografia de la pampa, por meio do antagonismo entre o leste e o oeste; isto é, entre o porto e o pampa (entre a Europa e o interior), mas também entre o centro tradicional e os novos "bairros-fronteira".

Em outras palavras, trata-se de uma definição que diante das leituras conservadoras do Centenário, que restringiam toda a problemática de Buenos Aires ao velho centro da cidade (e assinalavam o principal antagonismo entre o sul, antigo e malocado, e o norte, mais recente e aristocrático), tinha a virtude de reconhecer o surgimento conflituoso dos novos bairros populares, embora indo a reboque, como vimos, de todo o debate político, urbano e cultural da década de 1920, que já havia recentralizado a cidade popular. E o melhor exemplo de que La cabeza de Goliat retoma uma questão já resolvida na década anterior é o de que uma das maneiras com que volta a metaforizar esse antagonismo entre leste e oeste se dá pela confrontação entre "Florida" e "Boedo" - como se sabe, os nomes das duas ruas que, nos anos de 1920, situaram topograficamente a principal polêmica literária, mostrando, de passagem, a centralidade das representações da cidade na cultura portenha do início do século XX.

A polêmica era entre os escritores "da margem", que acreditavam encontrar nos arredores da rua Boedo - um bairro popular típico da mistura social, durante a primeira expansão de Buenos Aires - o ambiente ideal para seu programa de boemia proletária, além de também defenderem o realismo social diante das experiências da vanguarda martinfierrista, que 
tinha sua sede na Florida, a rua elegante do centro da cidade. $\mathrm{O}$ caráter artificial da polêmica já era notado na segunda metade dos anos de 1920, e Borges, martinfierrista, embora cultor dos bairros populares, expressou-o como ninguém: "Eu preferiria estar no grupo de Boedo, pois estava escrevendo sobre os subúrbios e a tristeza e os entardeceres. Contudo, fui informado por um dos conjurados que eu já estava designado para as hostes de Florida e que era demasiado tarde para trocar de lado" ${ }^{15}$.

Portanto, se em Radiografía de la pampa, no início da década de 1930, ainda podia fazer sentido desenvolver um sistema metafórico da cidade e da cultura, a partir da polêmica Florida/Boedo - o reformismo ainda estava buscando o reconhecimento urbanístico da nova centralidade real, já existente nos bairros como Boedo - a situação é muito diferente, por volta de 1940: o que era subúrbio, nas décadas de 1910 e 1920, deixou de sê-lo; Boedo já não é mais um "bairro-fronteira”, mas sim um típico bairro progressista de classe média, e surgira uma nova margem, em um "oeste” muito mais distante, fora dos limites da cidade Capital, pela qual La cabeça de Goliat não demonstra maior sensibilidade.

Mas, também no que se refere a essa temática, Martínez Estrada parece capaz de em seu anacronismo interpelar zonas mais contemporâneas do pensamento sobre a cidade. É evidente que sua retirada da cidade das décadas de 1910 e 1920 se baseia em sua recusa à expansão metropolitana, para a qual ele apresenta três significados: como sinônimo de crescimento de Buenos Aires às expensas do país; de extensão da neurose da cidade grande sobre tranquilas populações suburbanas; e de colonização artificial do campo. Ao mesmo tempo, não resta dúvida de que essa recusa era uma opção ante os debates do urbanismo: por exemplo, em La cabeza de Goliat, cita-se mais de uma vez Werner Hegemann, urbanista alemão que esteve em Buenos Aires em 1931, fundando as posições do reformismo urbano e do socialismo político ao defender uma visão favorável à expansão. Embora Martínez Estrada o mencione em tudo o que diz respeito às análises sobre o nível de adensamento permitido pelo Código de Edificação na cidade Capital, ele exclui qualquer referência à solução encontrada pelo urbanista alemão, no processo de expansão "natural" da metrópole sobre o território. Por sua vez, é em Lewis Mumford - outro autor de grande impacto nessa época, e logo introduzido em Buenos Aires pela revista Sur - que ele encontra o argumento teórico da impugnação ao crescimento da cidade, que se presta magnificamente às metáforas socioespaciais e à indignação moral contra o "tumor" da urbanização contemporânea - também expressas com ressonâncias
15. A citação de Borges é posterior e já foi utilizada sem referência de data por Horacio Salas, em seu estudo preliminar para a Revista Martín Fierro 1924-1927, edição facsimilar, Buenos Aires, Fondo Nacional de las Artes, 1995 , p. XII. No entanto, em seu clássico estudo "Boedo y Florida”, Adolfo Prieto cita outra frase semelhante de Borges, de 1927; ver Prieto (1969, p. 43). 
16. Ver Mumford (1960), em que um dos capítulos se intitula, em clara alusão a Spengler, "o presente pseudomórfico".

17. Can our cities survive? (Cambridge, Harvard University Press, 1942) constitui a reelaboração das conclusōes do IV Congresso Internacional de Arquitetura Moderna estabelecidas em 1933 em um barco entre Marselha e Atenas, e cujo modo didático de apresentação do caos metropolitano deu ampla popularidade a suas hipóteses (ainda desse IV Congresso surgiria a célebre Carta de Atenas, feita anonimamente por Le Corbusier: La Charte d'Athène, Paris, 1943, com prólogo de Jean Giraudoux).

18. A proposta do EPBA seguia as diretrizes do planejamento que os arquitetos argentinos Jorge Ferrari Hardoy e Jorge Kurchan realizaram, juntamente com Le Corbusier, em 1937, em Paris. Entre outras coisas, ela concentrava a edificação na zona central da cidade, promovendo um despovoamento radical dos arredores, que ficariam como zona de chácaras extraurbanas; sobre esse tema, ver a análise de Anahi Ballent (2005).

19. A publicação da análise do EPBA se deu, durante a queda do peronismo, em dois números consecutivos da $R e$ vista de Arquitectura, a publicação oficial da Sociedade Central de Arquitetos: "Evolución de Buenos Aires en el tiempo y en el espacio", n. 375 (1955) e n. 376-377 (1956). O epílogo de Sarrailh foi publicado na segunda parte, pp. 115 ss. spenglerianas -, ainda que suas críticas tenham a contrapartida de um projeto regionalista que encorajava um uso humanista da tecnologia e do território, e que, literalmente, teria obrigado Martínez Estrada a ver de outro modo a expansão suburbana da Grande Buenos Aires ${ }^{16}$.

De qualquer forma, para além das sutilezas, é possível notar que o espírito antiurbano de La cabeza de Goliat se articula plenamente com uma linha de crítica modernista do caos metropolitano, capaz de reunir as análises racionalistas de Le Corbusier - também feitas sobre Buenos Aires, quando de sua visita em 1929 - com o caráter organicista imposto no pensamento urbano nos anos de 1930, por meio da hegemonia do regionalismo anglosaxão. $\mathrm{O}$ melhor exemplo internacional dessa articulação se expressava, em 1941, com Can our cities survive? ${ }^{27}$, a análise catastrofista sobre a metrópole apresentada nos Estados Unidos por José Luis Sert, cujas ideias gozariam de grande popularidade durante as três décadas posteriores; já o exemplo local mais imediato seria o do Estudo do Plano de Buenos Aires (EPBA), o trabalho de planejamento que um grupo de discípulos de Le Corbusier realizou entre 1947 e 1949 no governo da cidade, propondo implantar uma reocupação radical do núcleo central da cidade ${ }^{18}$. O EPBA lançava um programa de moralização da grande cidade, muito semelhante ao de Martínez Estrada, cujo princípio elementar poderia ser reduzido a uma restauração do equilíbrio (cidade/natureza, passado/presente) perdido devido à irracionalidade tecnológica do industrialismo, que converteu a cidade em um "organismo monstruoso". Como dizia Eduardo Sarrailh, em um epílogo de 1955 à publicação do EPBA, já plenamente inserido no dualismo encontrado em La cabeza de Goliat, o urbanismo devia propiciar a "recuperação dos valores perdidos na busca de uma imperiosa necessidade de ordem urbana" ${ }^{19}$. A nostalgia como impulso ético e estético de um programa de renovação urbana: o livro de Martínez Estrada figura na publicação do EPBA, no âmbito de uma bem seleta bibliografia, mostrando um jogo de espelhos, muito frequente desde então, entre o ensaísmo e o urbanismo unidos por um conjunto de princípios: a busca da autenticidade, do equilíbrio e da ordem como superação das lógicas metropolitanas.

Até hoje, sempre abordamos La cabeza de Goliat em suas relações com a literatura sobre Buenos Aires, destacando seus saltos temporais na percepção da cidade: um livro que em alguns temas fundamentais parece atado a uma 
Buenos Aires de duas décadas antes de sua realização - a Buenos Aires que Martínez Estrada teria conhecido recém-chegado da província? -, mas que, por vezes, parece sintonizar enfoques contemporâneos e, até mesmo, antecipar outros. Mas, talvez, essa combinação entre anacronismo e iluminações antecipatórias seja uma característica do ensaio introspectivo sobre a cidade, como se a própria composição estratigráfica dos tempos da cidade, que sempre sucede por combinações entre o mais antigo e o mais novo, encontrasse uma réplica no pensamento figural, que tanto pode fixar-se em cenas originárias do passado, como pode dar lugar a uma dimensão projetável. Para empregar a definição de Aldo Rossi, seria como se o ensaísta produzisse uma "cidade análoga": uma figuração urbana que reordena todas as temporalidades da cidade, dispondo-as em uma cena imaginária estabelecida pela memória pessoal, mas que, nos casos em que a escrita consegue captar significados mais abarcantes, é capaz de transcender em memória social, disponibilizando um conjunto de representações passíveis de constante interpretação ${ }^{20}$. La cabeza de Goliat parece funcionar como um livro que discute em tempo presente com Sarmiento, os viajantes do Centenário, e Ortega y Gasset, abrindo-se às leituras como um baú de alfaiate no qual cada um pode encontrar o retalho que mais lhe convém.

Efetivamente, vimos que ao lado da predominante reposição anacrônica de temas, também é possível encontrar outras dimensões no livro - podendose aqui mencionar outras passagens em que Martínez Estrada combina a perspectiva etnográfica de Arlt e o encantamento poético de Borges (o capítulo "Calles de Buenos Aires"); em que identifica questóes ainda hoje fundamentais para a reflexão urbanística (o capítulo quase pastoral sobre a Costanera, "Lo más lejano"); ou em que cria definições de Buenos Aires, que parecem insinuar noções dos estudos da urbanização dependente (ao assinalar, por exemplo, que o tamanho da cidade deve ser compreendido em função de sua posição no mercado mundial de frutos e mercadorias [pp. 24-25]). Mas certamente seu principal insight reside na felicidade polissêmica do título: ao encontrar a denominação para o problema "capital" da Argentina, a partir do século XIX, Martínez Estrada acabou nomeando uma característica da urbanização latino-americana, que a sociologia urbana batizaria mais tarde, e com menos ventura do que o ensaísta, como a questão da "primazia urbana".

De qualquer forma, não se pode dizer que a sociologia urbana como tal tenha registrado impactos importantes de La cabeza de Goliat. Na realidade, o livro foi publicado no momento de maior prestígio do gênero ensaístico
20. Para uma análise da figura da "cidade análoga", proposta por Aldo Rossi, ver Gorelik (1999a). 
21. Na década de 1940, Martínez Estrada publica Sarmiento (1946), Nietzsche (1947), Las invariantes históricas del Facundo (1947) e Muerte y transfiguración del Martín Fierro (1948); e sua obra começa a ganhar projeção na América Latina, como o demonstra a edição por Fondo de Cultura de México desse último ensaio e também de seu livro sobre Guillermo Enrique Hudson, de 1951, além do fato de ele ter se tornado um colaborador regular de Cuadernos Americanos. Em 1948, publica-se "Reflexiones sobre el pecado original de América”, o artigo escrito por Héctor Álvarez Murena, que constitui o primeiro exemplo de que a obra de Martínez Estrada alcançou descendência e conexão com a nova geração.

22. A figura de Germani (1911-1979), de indiscutível centralidade na tradição sociológica argentina, foi objeto de renovada atenção nos últimos anos; cabe destacar o livro de Alejandro Blanco, Razónymodernidad. Gino Germani y la sociología en la Argentina (2006), que o mostra como uma figura culturalmente muito mais complexa do que a de difusor da sociologia funcionalista, sob a qual ficou estigmatizado. Ainda resta realizar, contudo, uma análise do papel de Germani no desenvolvimento dos estudos urbanos na Argentina, e sobretudo a importância e os efeitos da aproximação urbana na própria trajetória de Germani.

23. Sigo a análise realizada por Beatriz Sarlo em La batalla de las ideas, 1943-1973 (2001, pp. 80ss.), em que ela cita o trabalho de Gino Germani (1958). (em 1940, ninguém duvidava de que constituísse um gênero adequado para questionar a realidade social e cultural), introduzindo a década de maior produtividade e repercussão de seu autor, que, desde então, encontraria não só um público, como um núcleo de intelectuais jovens que o identificariam como mestre ${ }^{21}$. Entretanto, já no final da década de 1950, configura-se um novo campo de estudos urbanos, que se distanciaria do ensaísmo, apostando em um enfoque demográfico e socioeconômico, contemplado no título do primeiro trabalho de Gino Germani (1959) dedicado ao tema: o "processo de urbanização" 22 . Trata-se de uma perspectiva que buscava considerar as transformações urbanas como encarnação territorial dos processos resultantes da industrialização e do desenvolvimento. Tal enfoque - generalizado, durante esse período, em todo o Ocidente, e em particular nas cidades da América Latina, que se viam como especialmente propensas ao salto modernizador - aparecia como garantia da conversão dos estudos urbanos em uma disciplina científica com condições de, sob a aparência tecnocrática do planejamento, contribuir para a epopeia modernizadora da época, com um otimismo desenvolvimentista que as indagações produzidas pelo ensaísmo sobre a metrópole dificilmente conseguiriam alimentar.

No âmbito da "terceira cultura", essa poderia ser considerada a batalha mais árdua empreendida entre nós sobre as interpretações da cidade, ainda que ambas as tradições partissem de um núcleo de ideias básicas comuns, oferecido pela sociologia alemã da modernidade. De igual modo, Germani é um nome ao qual sempre se recorre para exemplificar uma tentativa de implantação das ciências sociais que precisou combater o ensaísmo para estabelecer um pensamento moderno em consonância com uma sociedade que se pretendia modernizada (em um continuum entre tipos de sociedade e tipos de habitus sociológico taxativamente cristalizado) ${ }^{23}$. Porém, ao menos na área dos estudos urbanos, é fácil comprovar que, mais do que uma batalha contra o ensaísmo, o que predominou foi a indiferença mútua: quase não há registro de referências críticas explícitas e, menos ainda, de debates. Por outro lado, os estudos centrados em uma versão cientificista de seu objeto vigoraram por breve tempo (o período clássico não se estende além de meados dos anos de 1970), não chegando a empanar o prestígio cultural do ensaísmo, nem a impedir a sua expansão. O urbanismo - que se poderia dizer, no que se refere ao planejamento, apresenta uma relação análoga à estabelecida entre o ensaísmo e a sociologia urbana - também manteve uma presença de destaque na reflexão sobre a cidade, apoiando-se, para tanto, na base ideoló- 
gica proveniente do ensaio. E, por fim, cabe lembrar que inclusive no interior do grupo de vanguarda dos estudos urbanos surgiram vozes alternativas que imprimiram uma valorização diferencial à tradição do ensaio.

Detenhamo-nos, para finalizar, nesta questão: é preciso recordar a precoce reivindicação do ensaio como chave para uma teoria da "cidade latinoamericana”, feita por Richard Morse, uma figura indubitavelmente marginal ao espírito modernizador dos estudos urbanos latino-americanos, mas sem a qual é difícil imaginar seu desenvolvimento como campo especializado. Já desde a década de 1950, Morse propôs a recuperação de algumas noções clássicas da tradição ensaística, como a de "cidade artificial”, vista em La cabeza de Goliat, valendo-se de um elenco muito heterogêneo de autores, de Jorge Basadre a Martínez Estrada. Tratou-se, certamente, de um uso bastante criativo dessa tradição, ao apresentar como verdade sociológica imutável - em outras palavras, a existência de uma matriz católico-ibérica resistente à modernidade anglo-saxã - aquilo que na maior parte dos ensaístas era motivo de denúncia, realizando uma inversão ideológica que define, de modo especular e deslocado, comparativamente a Germani, a relação entre tipo de sociedade e tipo de pensamento social: se a uma sociedade moderna corresponde a sociologia científica, Morse afirma que o ensaio é, então, mais apropriado não para uma sociedade tradicional, mas para uma sociedade (como seria o caso da latino-americana) que teria nascido pós-moderna (cf. Morse, 1957, 1971) ${ }^{24}$.

Entretanto, esse clamor por uma nova legitimidade do ensaio não se restringiu a essa inflexão ideológica, como se pode ver no seu uso intenso, mas notoriamente diverso, feito por José Luis Romero, em meados da década de 1960, em seus trabalhos sobre a cidade latino-americana, nos quais dialoga com uma linha mestra do ensaísmo argentino, que vai de Sarmiento a Martínez Estrada (cf. Prieto, 1989). Na realidade, o próprio Romero havia formado sua bagagem intelectual nas mesmas fontes da época que também impactaram o ensaísta: Simmel e, mais em geral, o vitalismo e o historicismo alemão introduzidos pela Revista de Occidente e por seu irmão alguns anos mais velho, Francisco Romero, filósofo e companheiro de Martínez Estrada em diversas atividades intelectuais - e manteria sempre um núcleo duro de fidelidade a essa matriz, em seu próprio trabalho historiográfico (cf. Altamirano, 2001). Mas, da mesma forma que não havia nada de tradicionalista na reivindicação do ensaio feita por Morse, mesmo quando tentava reposicionar ideologias tradicionais da América Latina, tampouco se pode compreender bem o uso do ensaio por Romero, sem lembrar que, ao mes-
24. Para uma análise da posição marginal e, ao mesmo tempo, fundamental de Morse no desenvolvimento da área de estudos urbanos na América Latina, ver Gorelik (2002). 
mo tempo, ele estava cumprindo um papel fundamental na renovação da história - sua cátedra de História Social foi uma das chaves da modernização universitária, a partir de 1955 - e, principalmente, na transformação da pesquisa social na Argentina, como o atesta sua parceria com Germani, no projeto de pesquisa sobre imigração, no final da década de 1950. Na realidade, essa dupla situação permite que Romero apresente uma posição singular sobre a cidade latino-americana, ao identificar na melodia modernizadora oriunda dos estudos sobre urbanização inspirados na Escola de Chicago as tonalidades comuns à sua formação ensaística: uma agenda de temas que poderiam ser reduzidos ao problema básico da dupla transição (tradição/ modernidade, campo/cidade), mas que, assim como Martínez Estrada, ele prefere situar no registro sarmientino de civilização e barbárie - e não resta dúvida de que sua capacidade como historiador norteia firmemente essa exploração pela literatura e pelo ensaio, resultando numa obra sobre a cidade muito mais sólida do que La cabeza de Goliat.

Será que isso significa que, em nosso caso, não seja adequada a periodização sobre a vigência do ensaio, traçada no início como hipótese mais geral? Tudo indica que no momento de maior radicalidade da visão cientificista sobre a cidade, assim como a partir do campo de estudos que a alentava, manteve-se entre nós uma tradição de leitura dos fenômenos urbanos que tornou mais simples do que alhures a reabilitação acadêmica do ensaio na década de 1980. E, talvez, isso permita explicar o impacto e a própria possibilidade de realização de uma obra como La ciudad letrada, de Ángel Rama, que novamente recolocou os termos do debate sobre a "terceira cultura” no polo da literatura.

\section{Referências Bibliográficas}

Altamirano, Carlos (org.). (1999), La Argentina en el siglo XX. Buenos Aires, Ariel. . (2001), "José Luis Romero y la idea de la Argentina aluvial". Prismas. Revista de historia intelectual, n. 5, Buenos Aires, Universidad Nacional de Quilmes.

Altamirano, Carlos \& Sarlo, Beatriz. (1983), "Martínez Estrada: de la crítica a Martín Fierro al ensayo sobre el ser nacional”. In: Ensayos argentinos: de Sarmiento a la vanguardia. Buenos Aires, Centro Editor de América Latina.

BALlent, Anahi. (2005), Las huellas de la politica: vivienda, ciudad, peronismo en Buenos Aires, 1943-1955. Buenos Aires, Universidad Nacional de Quilmes.

Blanco, Alejandro. (2006), Razón y modernidad: Gino Germani y la sociología en la Argentina. Buenos Aires, Siglo XXI. 
Borges, Jorge Luis. (1933), Revista multicolor de los sábados (suplemento cultural do jornal Crítica), ano I, n. 6, 16 de setembro.

Estrada, Ezequiel Martínez. (1969), "Sobre Radiografía de la pampa (preguntas y respuestas)". In: Leer y escribir. México, Moritz.

. (1983), La cabeza de Goliat.: microscopía de Buenos Aires. Buenos Aires, Losada. . (1993), Radiografía de la pampa. Edição crítica de Leo Pollman (org.). México, Colección Archivos.

Gálvez, Manuel. (2001), El diario de Gabriel Quiroga. 1a edição 1910. Buenos Aires, Alfaguara.

GERMANI, Gino. (1958), "Development and present state of sociology in Latin America”. Folheto do Instituto de Sociologia da Universidade de Buenos Aires.

. (1959), "El proceso de urbanización en la Argentina". Folheto do Instituto de Sociologia da Universidade de Buenos Aires.

GoreliK, Adrián. (1999a), "Historia de la ciudad e historia intelectual”. Prismas, n. 3, Buenos Aires, Universidad Nacional de Quilmes. . (1999b), "Buenos Aires y el país: figuraciones de una fractura”. In: AltamiRANO, Carlos (org.), La Argentina en el siglo XX. Buenos Aires, Ariel. . (2002), "La 'ciudad latinoamericana' como idea”. Punto de Vista, n. 73, Buenos Aires, agosto.

. (2004a), "Mapas de identidad. La imaginación territorial en el ensayo de interpretación nacional: de Ezequiel Martínez Estrada a Bernardo Canal Feijóo". In: Miradas sobre Buenos Aires. Buenos Aires, Siglo XXI.

(2004b), "Imágenes para una fundación mitológica. Apuntes sobre las fotografías de Horacio Cóppola”. In: . Miradas sobre Buenos Aires. Buenos Aires, Siglo XXI.

Gramuglio, María Teresa. (2001), "Posiciones, transformaciones y debates en la literatura". In: CatTaruzza, Alejandro (ed.), Nueva historia argentina, t. VII: Crisis económica, avance del Estado e incertidumbre politica (1930-1943). Buenos Aires, Sudamericana.

LEPENIES, Wolf. (1994), Las tres culturas: la sociología entre la literatura y la ciencia. México, Fondo de Cultura Económica.

Mallea, Eduardo. (1937), Historia de una pasión argentina. Buenos Aires, Sur.

Monegal, Emir Rodríguez. (1956), El juicio de los parricidas: la nueva generación argentina y sus maestros. Buenos Aires, Deucalión.

Morse, Richard. (1957), "La ciudad artificial”. Estudios Americanos, XIII, 67-68, Sevilla, abr./maio.

. (1971), La investigación urbana latinoamericana: tendencias y planteos. Buenos Aires, Ediciones SIAP. 
Mumford, Lewis. (1960), Técnica y civilización. $1^{\text {a }}$ edição 1934. Buenos Aires, Sur. NisBet, Robert. (1979), La sociología como forma de arte. Madri, Espasa Calpe.

Prieto, Adolfo. (1969), Estudios de literatura argentina. Buenos Aires, Galerna. . (1989), "Martínez Estrada, el interlocutor posible". Boletín del Instituto Ravignani 1, Buenos Aires, $1^{\circ}$ semestre.

Rella, Franco. (1984), Metamorfosi: immagini del pensiero. Milão, Feltrinelli.

RoJAs, Ricardo. (1971), La restauración nacionalista. 1a edição 1909. Buenos Aires, Peña Lillo.

ROMERO, José Luis. (1970), "Buenos Aires: una historia”. In: . La ciudad occi-

dental: culturas urbanas en Europa y América. Buenos Aires, Siglo XXI.

SAítTA, Sylvia. (1993), "Introdução". In: ARLt, Roberto, Aguafuertes porteñas. Buenos Aires, vida cotidiana. Buenos Aires, Alianza.

SARLO, Beatriz. (1983), "Vanguardia y criollismo: la aventura de Martín Fierro". In:

Altamirano, C. \& Sarlo, B. Ensayos argentinos: de Sarmiento a la vanguardia. Buenos Aires, Centro Editor de América Latina. . (2001), La batalla de las ideas (1943-1973). Biblioteca del Pensamiento Argentino VII. Buenos Aires, Ariel.

Sigal, León. (1993), "Itinerario de un autodidacto”. In: Estrada, Ezequiel Martínez, Radiografia de la pampa. Edição crítica de Leo Pollman (org.). México, Colección Archivos.

Vezzetti, Hugo. (2007), "El psicoanálisis en el siglo". Punto de vista, n. 88, Buenos Aires, ago.

VINAS, David. (1993), "Martínez Estrada, de Radiografia de la pampa hacia el Caribe”. In: Estrada, Ezequiel Martínez, Radiografía de la pampa. Edição crítica de Leo Pollman (org.). México, Colección Archivos. 


\section{Resumo}

A Buenos Aires de Ezequiel Martínez Estrada

O artigo propõe interpretar La cabeza de Goliat. Microscopía sobre Buenos Aires, o ensaio de Ezequiel Martínez Estrada, de 1940, como um reservatório de correntes muito diversificadas na literatura sobre Buenos Aires; isto é, como um precipitado de figurações da metrópole. Além disso, busca compreender como se formam e onde se originam as representações da cidade, e também como se manifestaram, no meio argentino e na temática urbana, as batalhas da "terceira cultura", na definição dada por Wolf Lepenies ao pensamento sociológico, sempre vacilante quanto à atração/oposição entre ciência e literatura. A “indagação sobre a metrópole”, como subgênero, traz para o primeiro plano as afinidades entre um modo de pensamento figural, como o proporcionado pelo ensaio, e uma realidade material, como a da cidade pletórica de configuraçôes simbólicas por meio das quais é possível interrogar os fatos sociais.

Palavras-chave: Ensaio; Estudos urbanos; Ezequiel Martínez Estrada; Buenos Aires.

\section{Abstract}

The Buenos Aires of Ezequiel Martínez Estrada

The article proposes to interpret La cabeza de Goliat. Microscopia sobre Buenos Aires, an essay by Ezequiel Martínez Estrada from 1940, as a reservoir of extremely diverse currents in the literature on Buenos Aires, containing many different figurations of the city. It also seeks to comprehend how the representations of the city were formed and from where they originated, as well as the ways in which the battles of the 'third culture' - in Wolf Lepenies's definition of sociological thought, forever wavering in the attraction/opposition between science and literature - were manifested in the context of urban Argentina. As a subgenre, the "inquiry into the metropolis" foregrounds the affinities between a mode of figural thought, like that provided by the essay, and a material reality, like the city with its plethora of symbolic configurations through which it is possible to examine social facts.

Keywords: Essay; Urban studies; Ezequiel Martínez Estrada; Buenos Aires.
Texto recebido e aprovado em 27/8/2009.

Adrián Gorelik é professor da Universidade de Quilmes e pesquisador do Conicet. É autor, entre outras publicações, de Miradas sobre Buenos Aires: historia culturaly crítica (Buenos Aires, Siglo XXI, 2004) e Das vanguardas a Brasilia: cultura urbana e arquitetura na América Latina (Belo Horizonte, Editora da UFMG, 2005). E-mail: adri an.gorelik@gmail.com. 